\title{
Treatment of Liver Metastases in Patients with Neuroendocrine Tumors of Gastroesophageal and Pancreatic Origin
}

\author{
Ping Gu, ${ }^{1}$ Jennifer Wu, ${ }^{1}$ Elliot Newman, ${ }^{2}$ and Franco Muggia $^{3}$ \\ ${ }^{1}$ Department of Hematology and Medical Oncology, NYU Cancer Institute, New York, NY 10016, USA \\ ${ }^{2}$ Department of General Surgery, NYU Medical Center New York, NY 10016, USA \\ ${ }^{3}$ Department of Medical Oncology, NYU Cancer Institute, New York, NY 10016, USA
}

Correspondence should be addressed to Franco Muggia, franco.muggia@nyumc.org

Received 1 August 2011; Revised 16 November 2011; Accepted 4 December 2011

Academic Editor: Wouter de Herder

Copyright () 2012 Ping Gu et al. This is an open access article distributed under the Creative Commons Attribution License, which permits unrestricted use, distribution, and reproduction in any medium, provided the original work is properly cited.

\begin{abstract}
Well-to-moderately differentiated neuroendocrine tumors of gastroesophageal and pancreatic origin (GEP-NETs) with liver metastasis are a heterogeneous group of malignancies for which a range of therapeutic options have been employed. Surgical resection of hepatic metastases or hepatic artery embolization may be beneficial in patients with hepatic-predominant metastatic disease. Patients with "carcinoid" syndrome and syndromes associated with functional pancreatic NET (PNET) can be effectively treated with somatostatin analogs. On the other hand, the efficacy of systemic chemotherapy for these patients is limited. A placebo-controlled, double-blind, prospective, and randomized study showed that octreotide LAR improves progression-free survival in patients with advanced midgut functional "carcinoids." In patients with advanced pancreatic NET, randomized, placebo-controlled studies have recently demonstrated that treatment with the tyrosine kinase inhibitor sunitinib or with mTOR inhibitor everolimus is associated with improved progression-free survival. Based on these studies, octreotide LAR, sunitinib, or everolimus are now considered as first-line therapeutic options in patients with advanced NET. Future studies will likely further define the role of these agents in patients with carcinoid liver metastasis and pancreatic NET liver metastasis.
\end{abstract}

\section{Introduction}

Neuroendocrine tumors of gastroesophageal and pancreatic origin (GEP-NETs) are a heterogeneous group of tumors characterized by their secretion of hormones or vasoactive peptides often resulting in specific hormone hyperfunction syndromes. NETs have recently been shown to be more common than previously suspected. In an analysis of the Surveillance, Epidemiology, and End Results (SEER) database, the estimated age-adjusted annual incidence of NET in 2004 was 5.25 per 100,000 people [1].

The prognosis and management of GEP-NETs is guided by histological classification. As a general rule, tumors with a high grade (grade 3), a mitotic count of more than 20 per 10 high-powered fields, or a Ki-67 proliferation index of more than $20 \%$ represent highly aggressive malignancies with a short clinical course and poor survival outcomes. The approach for these tumors is similar to that for small cell lung cancer and is not discussed in this review.

The focus of this review is the well-to-moderately differentiated GEP-NETs. These tumors can be subclassified into two general categories: pancreatic neuroendocrine tumors (PNETs) and others, mostly arising in the intestine, and often associated with the "carcinoid" syndrome. The terminology of "endocrine tumor" is replacing "neuroendocrine tumor" in pancreatic neuroendocrine tumors. And carcinoid is often linked to the secretion of serotonin and other vasoactive peptites resulting in "carcinoid" syndrome. This syndrome is manifested by episodic flushing, wheezing, diarrhea, and eventual right-sided valvular heart disease. Syndromes associated with hormone-secreting PNET can be manifested in insulinoma, glucagonoma, vasoactive intestinal peptide (VIP)-oma, and gastrinoma.

The majority of PNET occurs sporadically, but these tumors can also belong to a number of inherited syndromes 
associated with mutations in well-studied oncogenes and tumor suppressor genes. These syndromes include multiple endocrine neoplasia (MEN) types 1 and 2, von HippelLindau disease, and tuberous sclerosis [2]. Patients with NET with such syndromes may represent subgroups particularly responsive to novel therapies targeting the underlying genetic defect or pathway.

GEP-NETs typically have an indolent natural history, even in the setting of metastasis. The treatment of patients with localized NET is primarily surgical. There are no data that demonstrate a benefit associated with adjuvant therapies. However, GEP-NETs commonly metastasize to liver, with up to $44 \%$ of patients developing neuroendocrine liver metastasis (NELM) over the course of their disease [3]. This review summarizes the current approach to NELM based on clinical trials in the past 10 years, emphasizing the differences between NELM arising from carcinoid and those from PNET.

\section{Locoregional Therapies}

2.1. Surgical Resection. Symptom control and improved quality of life and overall survival can be achieved by the reduction of circulating hormone levels via functional hormonal blockade, transarterial chemoembolization (TACE), or radiofrequency thermal ablation (RFA), thus obviating surgery. However, hepatic resection is often considered in patients with limited hepatic disease. If more than $90 \%$ of the tumor mass can be removed, these patients have an outcome similar to those with complete resection (resection of all visible hepatic tumors) $[4,5]$.

Mayo et al. [6] reported the outcomes of 339 patients from 8 major hepatobiliary centers who underwent surgical management for neuroendocrine liver metastasis (NELM) from 1985 to 2009. Major hepatectomy was performed in $45 \%$ of patients, and $14 \%$ underwent a second liver operation. Median survival was 125 months, with overall 5- and 10-year survival of $74 \%$, and $51 \%$, respectively. Disease recurred in $94 \%$ of patients at 5 years. Patients with hormonally functional NET who had R0/R1 resection benefited the most from surgery $(P=0.01)$. In a multivariate analysis, synchronous disease, nonfunctional NET hormonal status, and extrahepatic disease were independent predictors of worse survival $(P<0.05)$. Thus, while surgical resection for NELM is associated with prolonged survival, the majority of patients will develop recurrent disease. Patients with hormonally functional hepatic metastasis without prior extrahepatic or synchronous disease derive the greatest survival benefit from surgical management.

2.2. Radiofrequency Thermal Ablation (RFA). Mazzaglia et al. [7] reported a prospective trial of 80 RFA sessions which was performed in 63 patients with NELM. Tumor types included 36 "carcinoid", 18 pancreatic islet cell, and 9 medullary thyroid cancer. RFA was performed 1.6 years after the diagnosis of liver metastases. Median number of lesions treated was 6 . The majority (49\%) underwent 1 ablation session, and 14 (22\%) had repeat sessions caused by disease progression. Fifty-seven percent of patients exhibited symptoms. One week postoperatively $92 \%$ of patients reported at least partial symptom relief, and $70 \%$ had significant or complete relief. Duration of symptom control was 11 months. Larger dominant liver tumor size and male gender adversely impacted survival $(P<0.05)$. Median survival times were 11.0 years after diagnosis of primary tumor, 5.5 years after diagnosis of NELM, and 3.9 years after first RFA. RFA, therefore, provides effective local control with prompt symptomatic improvement.

2.3. Liver Transplantation. If metastases are limited to the liver, orthotopic liver transplantation (OLT) is a viable treatment option [8]. OLT is currently offered to patients with unresectable metastases or for palliation of medically uncontrollable symptoms. Very few centers had reported experience representing more than 10 patients. Lehnert reviewed 103 cases who underwent OLT for metastases of NET in the largest review so far. Overall, 2-year and 5-year survival for all 103 patients was $60 \%$ and $47 \%$, respectively, but recurrence-free 5-year survival did not exceed $24 \%$. Three favorable prognostic factors were identified: age less than 50 years old, primary tumor location in lung or bowel, and pretransplant somatostatin therapy. In contrast, extensive abdominal operations were associated with poor prognosis. Thus, liver transplantation may be indicated in highly selected patients to provide immediate relief of otherwise intractable pain or hormone-related symptoms. OLT has no clear role in the routine treatment of patients with NET due to relatively high rates of tumor recurrence [9-11].

\subsection{Transarterial Embolization (TAE)/Transarterial Che-} moembolization (TACE). Hepatic arterial embolization is commonly used as a palliative technique in patients with hepatic metastases who are not candidates for surgical resection. Hepatic artery embolization is based on the principle that tumors in the liver derive most of their blood supply from the hepatic artery, whereas healthy hepatocytes derive most of their blood supply from the portal vein. Embolization response rates are measured either by a decrease in hormonal secretion or by radiographic regression and are generally greater than $50 \%[12,13]$. In one of the largest series of 81 patients underwent embolization or chemoembolization for tumors labeled as "carcinoids" (likely of intestinal origin), the median duration of response was 17 months, and the probability of progression-free survival at 1,2 , and 3 years was $75 \%, 35 \%$, and $11 \%$, respectively [12].

Objective tumor responses have been noted in $33 \%$ to $67 \%$ of patients (Table 1). The variation of objective tumor response is related to the heterogeneous nature of tumors, various combination of cytotoxic agents, uncontrolled concomitant use of somatostatin analogues, and the difference in hepatic tumor burden. 
TABLE 1: Selected clinical studies of transarterial embolization (TAE)/transarterial chemoembolization (TACE) in metastatic NET.

\begin{tabular}{|c|c|c|c|c|}
\hline Author (yr) & $\begin{array}{l}\text { No. of } \\
\text { patients }\end{array}$ & Disease & Therapy & $\begin{array}{l}\text { Complete/partial } \\
\text { response }\end{array}$ \\
\hline Ruszniewski et al. [14] (1993) & 24 & Carcinoid/PNET & TACE & $33 \%$ \\
\hline Wängberg et al. [15] (1996) & 40 & Carcinoid & TAE & $42.5 \%$ \\
\hline Gupta et al. [12] (2003) & 81 & Carcinoid & TACE/TAE & $67 \%$ \\
\hline Strosberg et al. [16] (2006) & 84 & Carcinoid/PNET & TAE & $48 \%$ \\
\hline Marrache et al. [17] (2007) & 38 & Carcinoid/PNET & TACE/TAE & $37 \%$ \\
\hline Ho et al. [18] (2007) & 33 & Carcinoid/PNET & TACE/TAE & $46 \%$ \\
\hline
\end{tabular}

TABLE 2: Selected clinical trials of cytotoxic chemotherapy in advanced PNET**.

\begin{tabular}{|c|c|c|c|c|c|}
\hline Regimen & $\begin{array}{c}\text { No. of } \\
\text { patients }\end{array}$ & $\begin{array}{c}\text { Tumor } \\
\text { response } \\
\text { rates }(\%)\end{array}$ & $\begin{array}{c}\text { Median } \\
\text { PFS } \\
\text { month }\end{array}$ & $\begin{array}{l}\text { Complete/partial } \\
\text { response }\end{array}$ & Author (yr) \\
\hline \multicolumn{6}{|l|}{ Prospective studies } \\
\hline Chlorozotocin & 33 & 30 & 17 & 18 & Moertel et al. [19] (1992) \\
\hline $\mathrm{STZ}+5 \mathrm{FU}$ & 33 & 45 & 14 & 16.8 & \\
\hline $\mathrm{STZ}+\mathrm{DOX}$ & 36 & 69 & 18 & 26.4 & \\
\hline DTIC & 50 & 34 & NR & 19.3 & Ramanathan et al. [20] (2001) \\
\hline \multicolumn{6}{|l|}{ Retrospective studies } \\
\hline $\mathrm{STZ}+5 \mathrm{FU}+\mathrm{DOX}$ & 84 & 39 & 18 & 37 & Kouvaraki et al. [21] (2004) \\
\hline $\begin{array}{l}\text { TMZ various } \\
\text { chemotherapy }\end{array}$ & 53 & 34 & 13.6 & 35.3 & Kulke et al. [22] (2009) \\
\hline $\mathrm{TMZ}+$ Capecitabine & 30 & 70 & 18 & NR & Strosberg et al. [23] (2010) \\
\hline
\end{tabular}

${ }^{* *}$ Several of the early studies often assessed tumor response and PFS by clinical and not imaging parameters.

PFS: progression-free survival, STZ: streptozocin, 5FU: 5-flurouracil, DOX: doxorubicin, DTIC: dacarbazine, TMZ: temozolomide, NR: not reported.

Recent research has investigated the use of ${ }^{90} \mathrm{Y}$ radioembolization to treat unresectable NELM. Kennedy et al. [24] reported that imaging response demonstrated stable lesions in $22.7 \%$, partial response in $60.5 \%$, complete response in $2.7 \%$, and progressive disease in $4.9 \%$ of patients with only mild associated toxicity. The median survival from time of treatment was 70 months. Objective respond rate (complete and partial response) were observed in $50 \%$ of patients in a prospective studies, in which 32 patients were treated with ${ }^{90} \mathrm{Y}$ microspheres [25].

\section{Systemic Therapies}

3.1. Somatostatin Analogs. Most neuroendocrine tumors $(>80 \%)$ express a high density of somatostatin receptors (SSTR 1-5). Native somatostatin has not been useful in clinical practice due to its short half-life ( $<2$ minutes). In 1980, Bauer et al. synthesized a somatostatin analog called octreotide, constituting an octapeptide with 3 unnatural amino acids, whereby the compound became resistant to metabolic degradation and presented a half-life of 3 to 4 hours in circulation. This peptide binds with high affinity to SSTR2 and SSTR5 and, therefore, inhibits the secretion of peptides and amines from neuroendocrine cells. In an initial study, the subcutaneous administration of the somatostatin analog octreotide, administered at a dosage of $150 \mathrm{mg} 3$ times a day, improved the symptoms of "carcinoid" syndrome in $88 \%$ of patients [26].

Octreotide has been widely used in oncology for almost 3 decades and is the most effective drug in inhibiting clinical symptoms related to hypersecretion of amines and peptides in NET. A long-acting depot form of octreotide (octreotide LAR), which can be administered on a monthly basis, has gained popularity. Octreotide therapy results in remission or stabilization of tumor markers, such as serotonin and chromogranin A, in approximately $60 \%$ to $70 \%$ of patients $[27,28]$.

PROMID [29] is the first randomized prospective trial demonstrating a possible antitumor effect for octreotide LAR compared with a placebo in patients with well-differentiated neuroendocrine tumors of midgut origin. A total of 85 patients with inoperable or metastatic well-differentiated midgut neuroendocrine tumors (carcinoid tumor) were randomized to receive either octreotide LAR $30 \mathrm{mg}$ monthly or placebo. Median time to tumor progression was significantly longer for patients receiving octreotide (14.3 versus 6 months). This study supports an antiproliferative effect in well-differentiated midgut carcinoid tumors, with stabilization being the most frequently observed therapeutic response. However, only less than $10 \%$ tumor mass in the liver along with resected primary tumors responded to treatment. There was no significant difference in time to tumor progression between octreotide LAR and placebo in 
TABLE 3: Selected randomized trials of targeted therapy in advanced neuroendocrine tumors.

\begin{tabular}{|c|c|c|c|c|c|}
\hline Regimen & $\begin{array}{l}\text { No. of } \\
\text { patients }\end{array}$ & $\begin{array}{l}\text { Tumor } \\
\text { response } \\
\text { rates }(\%)\end{array}$ & $\begin{array}{l}\text { Median PSF } \\
\text { (months) }\end{array}$ & $\begin{array}{l}\% \text { of } \\
\text { NELM }\end{array}$ & $\begin{array}{l}\text { Author } \\
\text { (yr) }\end{array}$ \\
\hline \multicolumn{6}{|l|}{ PNET } \\
\hline Sunitinib $37.5 \mathrm{mg}$ po qd & 86 & 9 & $\begin{array}{c}11.4 \\
(P<0.001)\end{array}$ & $\begin{array}{c}71 \\
(61 / 86)\end{array}$ & $\begin{array}{l}\text { Raymond et } \\
\text { al. [35] } \\
(2011)\end{array}$ \\
\hline Placebo (+ best supportive care) & 85 & 0 & 5.5 & $\begin{array}{c}54 \\
(46 / 85)\end{array}$ & \\
\hline Everolimus $10 \mathrm{mg}$ po qd & 207 & 5 & $\begin{array}{c}11 \\
(P<0.001)\end{array}$ & $\begin{array}{c}92 \\
(190 / 207)\end{array}$ & $\begin{array}{c}\text { Yao et al. [36] } \\
(2011)\end{array}$ \\
\hline Placebo (+ best supportive care) & 203 & 2 & 4.6 & $\begin{array}{c}92 \\
(187 / 203)\end{array}$ & \\
\hline \multicolumn{6}{|l|}{ Everolimus $10 \mathrm{mg}$ po qd } \\
\hline $\begin{array}{l}\text { Everolimus } 10 \mathrm{mg} \text { po qd + } \\
\text { Bevacizumab } 10 \mathrm{mg} / \mathrm{kg} \\
\text { every other week }\end{array}$ & $\begin{array}{l}\text { GALGB } \\
80701\end{array}$ & Ongoing & & & \\
\hline \multicolumn{6}{|l|}{ Carcinoid } \\
\hline Octreotide LAR & 42 & 2 & $\begin{array}{c}14.3 \\
(P<0.001)\end{array}$ & $\begin{array}{c}83 \\
(35 / 42)\end{array}$ & $\begin{array}{l}\text { Rinke et al. } \\
\text { [29] (2009) }\end{array}$ \\
\hline Placebo & 43 & 2 & 6.0 & $\begin{array}{c}88 \\
(38 / 43)\end{array}$ & \\
\hline Everolimus + octreotide LAR & 187 & $\begin{array}{l}\text { Radiant-2 } \\
\text { accrual } \\
\text { completed }\end{array}$ & $\begin{array}{c}\text { Final report } \\
\text { pending }\end{array}$ & & \\
\hline Placebo + octreotide LAR & 191 & & & & \\
\hline Octreotide + bevacizumab & $\begin{array}{l}\text { SWOG } \\
\text { S0518 }\end{array}$ & & & & \\
\hline Octreotide + placebo & & & & & \\
\hline
\end{tabular}

patients with larger tumor burden. The authors concluded that newly diagnosed NET with a low hepatic tumor burden and resected primary tumor were candidates for treatment with octreotide LAR.

The high rate of somatostatin receptor expression in NETs provides the rationale for peptide receptor radionuclide therapy (PRRT) as a treatment modality for patients with inoperable or metastatic disease. Several radiolabeled somatostatin analogs have been developed to treat patients with somatostatin receptor-positive metastatic tumors. The most frequently used radionuclides include yttrium $\left({ }^{90} \mathrm{Y}\right)$ and lutetium $\left({ }^{177} \mathrm{Lu}\right)$, which differ from one another in terms of emitted particles, particle energy, and tissue penetration. ${ }^{90} \mathrm{Y}$ emits $\beta$-radiation has a range of $12 \mathrm{~mm}$, and ${ }^{177} \mathrm{Lu}$ emits both $\beta$-radiation and $\gamma$-radiation and has a range of $2 \mathrm{~mm} .{ }^{177} \mathrm{Lu}$-DOTA, $\mathrm{Tyr}^{3}$-octreotate has since been utilized in the treatment of over 500 patients with GEP-NETs. Efficacy results, reported for 310 patients and 89\% (276/310) presented liver metastasis, suggest an overall tumor response rate of up to $30 \%$. However, all PRRTs using yttrium $\left({ }^{90} \mathrm{Y}\right)$ and lutetium $\left({ }^{177} \mathrm{Lu}\right)$ are not randomized, prospective studies and majority of patients are carcinoid [30-33].

3.2. Cytotoxic Chemotherapy. In a Phase II/III study of 249 patients with advanced "carcinoid" tumors, patients were randomized to receive either streptozocin/5-FU or 5FU/doxorubicin [34]. The response rates were $16 \%$ and $15.9 \%$, respectively. Although there was a slightly longer survival time associated with streptozocin/5-FU (24.3 versus 15.7 months) in this trial, over one-third of the patients treated with streptozocin developed renal toxicity. Thus, streptozocin-based regimens are not recommended in the first-line treatment of metastatic "carcinoid" tumors.

However, patients with advanced PNET may respond well to treatment with streptozocin and other alkylating agents. In a randomized trial, the combination of streptozocin and doxorubicin was associated with an overall response rate of $69 \%$ and a survival benefit, with median overall survival of 2.2 years [19]. A retrospective analysis of 84 patients with either locally advanced or metastatic PNET receiving a three-drug regimen of streptozocin, 5-FU, and doxorubicin showed that this regimen was associated with an overall response rate of $39 \%$ and a median survival of 37 months [21].

Temozolomide is an orally alkylating agent with a mechanism of action similar to streptozocin and dacarbazine. Retrospective studies suggest comparable progression-free survival (PFS) and overall survival (OS) between streptozocin and temozolomide-based regimens in patients with advanced PNET (Table 2). Prospective studies using 
temozolomide-based regimens in patients with advanced PNET are ongoing.

\subsection{Targeted Therapies for Pancreatic Neuroendocrine Tumors.} Studies of targeted therapies in PNET have, to date, focused primarily on inhibitors of the vascular endothelial growth factor (VEGF) or mammalian target of rapamycin- (mTOR) signaling pathways. Two phase III randomized studies suggested that treatment with these agents is associated with improvements in progression-free survival (PFS).

3.4. VEGF Pathway Inhibitors. Bevacizumab which targets VEGF and three tyrosine kinase inhibitors: pazopanib, sorafenib, and sunitinib-all with activity against VEGF receptor (VEGFR) - have been evaluated in prospective trials of patients with advanced PNET.

Bevacizumab is a recombinant humanized monoclonal antibody that binds to and neutralizes the biologic activity of human VEGF-A. In a randomized phase II study conducted at M.D. Anderson, 44 patients on stable doses of octreotide were randomly assigned to 18 weeks of treatment with bevacizumab or pegylated interferon alfa-2b (PEG IFN). A rapid and sustained decrease was observed in tumor perfusion following treatment with octreotide and bevacizumab, as measured in functional computed tomography. Clinical activity was evident by a response rate of $18 \%$ and an improved PFS rate at week 18 (95\% versus $68 \% ; P=0.02)$. Bevacizumab therapy therefore provides an advantage in objective responses, reduction of tumor blood flow, and PFS in patients with carcinoid compared to PEG IFN treatment [37].

NETs frequently express VEGFR-2 and platelet-derived growth factor receptor receptor- $\beta$ (PDGFR- $\beta$ ). Sorafenib, a small-molecule inhibitor of the VEGFR-2 and PDGFR- $\beta$ tyrosine kinase domains, is a rational targeted therapy to be evaluated in NET. Hobday, et al. [38] reported a phase II study in 2007 ASCO using sorafenib in patients exposed to prior interferon and prior or concurrent octreotide at a stable dose. Patients received sorafenib $400 \mathrm{mg}$ orally BID. A total of 93 patients were enrolled: (50 carcinoid and 43 PNET). For patients evaluable for the primary endpoint, 4 of $41(10 \%)$ carcinoid patients and 4 of $41(10 \%)$ PNET patients had a partial response (PR). There were 3 minor responses (MR $=20-29 \%$ decrease in sum of target lesion diameters) in carcinoid patients and $9 \mathrm{MRs}$ in PNET patients and this led to PR + MR rate of $17 \%$ for carcinoid patients and 32\% for PNET patients. Sorafenib at $400 \mathrm{mg}$ orally twice a day in this study demonstrated modest activity in metastatic NET.

VEGF is a key driver of angiogenesis in PNET. Tissue from malignant PNET also shows widespread expression of PDGFRs $\alpha$ and $\beta$, stem-cell factor receptor (ckit), and VEGFR-2 and VEGFR-3. Sunitinib inhibits these kinases and delays tumor growth in a RIP1-Tag2-transgenic mouse model of pancreatic islet-cell tumors by reducing endothelial-cell density and pericyte coverage of tumor vessels.

Sunitinib was evaluated in a multi-institutional phase II study enrolling 109 patients with advanced NET. Patients received sunitinib, administered orally at $50 \mathrm{mg}$ once daily for 4 weeks, followed by a 2 -week off period. Partial responses were observed in $2 \%$ of the carcinoid cohort and $16 \%$ of the PNET cohort [39]. Based on the encouraging response rate in this phase II study, an international randomized phase III study was conducted to confirm the activity of sunitinib in PNET. The study was discontinued prior to a planned interim analysis after enrollment of 171 patients, 86 of them received sunitinib, and 85 received placebo. The trial was terminated early because of the risk of serious adverse events, disease progression, and death among patients receiving placebo. The early discontinuation of the study precluded the definitive conclusion on differences in PFS durations between the treatment and placebo groups. Nevertheless, analysis of the available data demonstrated that treatment with sunitinib was associated with a remarkable median PFS of 11.4 months, as compared with 5.5 months for placebo $(P=0.0001)$ [35].

Pazopanib is an oral tyrosine kinase inhibitor of VEGFR, PDGFR, and KIT with both antiangiogenic and antitumoral activity. Pazopanib was evaluated in a prospective study enrolling 51 NET patients (29 with PNET and 22 with carcinoid) on stable doses of octreotide-LAR. Patients received pazopanib at a dose of $800 \mathrm{mg}$ daily. The response rate among patients with PNET was 17\%; no patients with carcinoid experienced a radiographic response (by RECIST). PFS rate at week 24 was $76 \%$ (80\% PNET and $71 \%$ carcinoid). Median PFS times were 12.7 and 11.7 months, for carcinoid and PNET patients, respectively. Encouraging PFS durations in both carcinoid and PNET patients in this study suggested that treatment with pazopanib and octreotide seemed feasible and associated with tumor regression in patients with PNET [40].

3.5. $m$ TOR Inhibitors. $\mathrm{mTOR}$ is a serine-threonine kinase that participates in the regulation of cell growth, proliferation, and apoptosis. Signaling through the PI3K/AKT/mTOR pathway leads to increased translation of proteins regulating cell-cycle progression and metabolism. This enzyme also mediates downstream signaling from a number of pathways, including the VEGF and insulin-like growth factor (IGF) signaling implicated in NET growth. The inhibition of mTOR prevents phosphorylation of key cell-cycle control proteins, leading to G1 growth arrest.

Temsirolimus and everolimus are rapamycin derivatives which were evaluated in NET. Weekly intravenous temsirolimus was associated with a response rate of $5.6 \%$ in a study of 37 patients with advanced progressive NET. Outcomes were similar between patients with carcinoid and PNET [41].

Everolimus was initially evaluated in a single-institution study, in which 30 patients with "carcinoid" tumors of intestinal origin and 30 with pancreatic PNET received doses of 5 or $10 \mathrm{mg}$ daily plus depot octreotide $(30 \mathrm{mg}$ every 4 weeks). The overall tumor response rate in evaluable patients was $17 \%$ in carcinoid and $27 \%$ in PNET [42].

In a follow-up international phase II study (RADIANT1), 160 patients with advanced PNET and evidence of 
RECIST-defined progression following chemotherapy were enrolled. In this nonrandomized study, treatment with everolimus was associated with an overall response rate of $4.4 \%$ and PFS duration of 16.7 months in those patients receiving octreotide. Among patients who did not receive octreotide, the response rate was $9.6 \%$, and the PFS duration was 9.7 months [43].

A subsequent phase III study randomized 410 patients with progressive advanced PNET (RADIANT-3) to everolimus or placebo. This study demonstrated significant improvements in PFS (the primary endpoint) associated with everolimus as compared to placebo [(11 months versus 4.6 months $(P<0.0001)]$. The overall tumor response rate associated with everolimus in this study was 5\% [36]. A subgroup analysis of Japanese patients (23 patients received everolimus and 17 patients were in placebo arm) in the same RADIANT-3 study showed a significant 17 months improvement in PFS (19.45 versus 2.83 months) and an $81 \%$ risk reduction of progression or death (HR $0.19,95 \%$ CI 0.08-0.48, $P<0.001$ ) [44]. Phase III-randomized trials of biological targeted therapy in advanced neuroendocrine tumors are summarized in Table 3.

3.6. Combination of Target Therapies. Ongoing studies are evaluating combinations of targeted agents in patients with advanced neuroendocrine tumors. The combination of everolimus + bevacizumab was shown to be well tolerated and associated with antitumor activity (overall response rate $26 \%$ ) in an initial phase II study enrolling patients with low- or intermediate-grade neuroendocrine tumors [43]. Other combination-advanced PNETs includes everolimus + temozolomide [45] and everolimus + octreotide [42].

\section{Conclusions}

Different therapeutic options have been employed for wellto-moderately differentiated NELM. Surgical resection of hepatic metastases or hepatic artery embolization can be helpful in patients with hepatic-predominant metastatic disease. Symptoms of hormonal excess, such as "carcinoid" syndrome and syndromes associated with functional PNET, can be effectively treated with somatostatin analogs. Treatment with the somatostatin analog octreotide has been shown to improve progression-free survival in patients with advanced midgut carcinoid tumors. Patients with NELM may also respond to treatment with streptozocin or temozolomidebased therapy but need to be reassessed using standard criteria of response. In patients with advanced PNET, randomized, placebo-controlled studies have recently demonstrated that treatment with the tyrosine kinase inhibitor sunitinib or with the MTOR inhibitor everolimus is associated with improved PFS. Initial phase II studies have also suggested activity associated with VEGF pathway and mTOR inhibitors in patients with neuroendocrine tumors of other origins including intestinal "carcinoids." Future studies will likely define the utility of combinations of these agents in the treatments of patients with NELM.

\section{References}

[1] J. C. Yao, M. Hassan, A. Phan et al., "One hundred years after "carcinoid": epidemiology of and prognostic factors for neuroendocrine tumors in 35,825 cases in the United States," Journal of Clinical Oncology, vol. 26, no. 18, pp. 3063-3072, 2008.

[2] D. S. Klimstra, I. R. Modlin, D. Coppola, R. V. Lloyd, and S. Suster, "The pathologic classification of neuroendocrine tumors: a review of nomenclature, grading, and staging systems," Pancreas, vol. 39, no. 6, pp. 707-712, 2010.

[3] I. M. Modlin, K. D. Lye, and M. Kidd, "A 5-decade analysis of 13,715 carcinoid tumors," Cancer, vol. 97, no. 4, pp. 934-959, 2003.

[4] F. G. Que, D. M. Nagorney, K. P. Batts, L. J. Linz, and L. K. Kvols, "Hepatic resection for metastatic neuroendocrine carcinomas," American Journal of Surgery, vol. 169, no. 1, pp. 36-43, 1995.

[5] B. Dousset, O. Saint-Marc, J. Pitre, O. Soubrane, D. Houssin, and Y. Chapuis, "Metastatic endocrine tumors: medical treatment, surgical resection, or liver transplantation," World Journal of Surgery, vol. 20, no. 7, pp. 908-915, 1996.

[6] S. C. Mayo, M. C. De Jong, C. Pulitano et al., "Surgical management of hepatic neuroendocrine tumor metastasis: results from an international multi-institutional analysis," Annals of Surgical Oncology, vol. 17, no. 12, pp. 3129-3136, 2010.

[7] P. J. Mazzaglia, E. Berber, M. Milas, and A. E. Siperstein, "Laparoscopic radiofrequency ablation of neuroendocrine liver metastases: a 10-year experience evaluating predictors of survival," Surgery, vol. 142, no. 1, pp. 10-19, 2007.

[8] F. G. I. van Vilsteren, E. S. Baskin-Bey, D. M. Nagorney et al., "Liver transplantation for gastroenteropancreatic neuroendocrine cancers: defining selection criteria to improve survival," Liver Transplantation, vol. 12, no. 3, pp. 448-456, 2006.

[9] T. Lehnert, "Liver transplantation for metastatic neuroendocrine carcinoma: an analysis of 103 patients," Transplantation, vol. 66, no. 10, pp. 1307-1312, 1998.

[10] E. J. Grossman and J. M. Millis, "Liver transplantation for non-hepatocellular carcinoma malignancy: indications, limitations, and analysis of the current literature," Liver Transplantation, vol. 16, no. 8, pp. 930-942, 2010.

[11] Y. P. Le Treut, E. Grégoire, J. Belghiti et al., "Predictors of long-term survival after liver transplantation for metastatic endocrine tumors: an 85-case French multicentric report," American Journal of Transplantation, vol. 8, no. 6, pp. 12051213, 2008.

[12] S. Gupta, J. C. Yao, K. Ahrar et al., "Hepatic artery embolization and chemoembolization for treatment of patients with metastatic carcinoid tumors: the M.D. Anderson experience," Cancer Journal, vol. 9, no. 4, pp. 261-267, 2003.

[13] C. Loewe, M. Schindl, M. Cejna, B. Niederle, J. Lammer, and S. Thurnher, "Permanent transarterial embolization of neuroendocrine metastases of the liver using cyanoacrylate and lipiodol: assessment of mid- and long-term results," American Journal of Roentgenology, vol. 180, no. 5, pp. 13791384, 2003.

[14] P. Ruszniewski, P. Rougier, A. Roche et al., "Hepatic arterial chemoembolization in patients with liver metastases of endocrine tumors: a prospective Phase II study in 24 patients," Cancer, vol. 71, no. 8, pp. 2624-2630, 1993.

[15] B. Wängberg, G. Westberg, U. Tylén et al., "Survival of patients with disseminated midgut carcinoid tumors after aggressive 
tumor reduction," World Journal of Surgery, vol. 20, no. 7, pp. 892-899, 1996.

[16] J. R. Strosberg, J. Choi, A. B. Cantor, and L. K. Kvols, "Selective hepatic artery embolization for treatment of patients with metastatic carcinoid and pancreatic endocrine tumors," Cancer Control, vol. 13, no. 1, pp. 72-78, 2006.

[17] F. Marrache, M. P. Vullierme, C. Roy et al., "Arterial phase enhancement and body mass index are predictors of response to chemoembolisation for liver metastases of endocrine tumours," British Journal of Cancer, vol. 96, no. 1, pp. 49-55, 2007.

[18] A. S. Ho, J. Picus, M. D. Darcy et al., "Long-term outcome after chemoembolization and embolization of hepatic metastatic lesions from neuroendocrine tumors," American Journal of Roentgenology, vol. 188, no. 5, pp. 1201-1207, 2007.

[19] C. G. Moertel, M. Lefkopoulo, S. Lipsitz, R. G. Hahn, and D. Klaassen, "Streptozocin-doxorubicin, streptozocinfluorouracil, or chlorozotocin in the treatment of advanced islet-cell carcinoma," New England Journal of Medicine, vol. 326, no. 8, pp. 519-523, 1992.

[20] R. K. Ramanathan, A. Cnaan, R. G. Hahn, P. P. Carbone, and D. G. Haller, "Phase II trial dacarbazine (DTIC) in advanced pancreatic islet cell carcinoma. Study of the Eastern Cooperative Oncology Group-E6282," Annals of Oncology, vol. 12, no. 8, pp. 1139-1143, 2001.

[21] M. A. Kouvaraki, J. A. Ajani, P. Hoff et al., "Fluorouracil, doxorubicin, and streptozocin in the treatment of patients with locally advanced and metastatic pancreatic endocrine carcinomas," Journal of Clinical Oncology, vol. 22, no. 23, pp. 4762-4771, 2004.

[22] M. H. Kulke, J. L. Hornick, C. Frauenhoffer et al., "O6 -methylguanine DNA methyltransferase deficiency and response to temozolomide-based therapy in Patients with Neuroendocrine Tumors," Clinical Cancer Research, vol. 15, no. 1, pp. 338-345, 2009.

[23] J. R. Strosberg, R. L. Fine, J. Choi et al., "First-line chemotherapy with capecitabine and temozolomide in patients with metastatic pancreatic endocrine carcinomas," Cancer, vol. 117, no. 2, pp. 268-275, 2011.

[24] A. S. Kennedy, W. A. Dezarn, P. McNeillie et al., "Radioembolization for unresectable neuroendocrine hepatic metastases using resin 90Y-microspheres: early results in 148 patients," American Journal of Clinical Oncology, vol. 31, no. 3, pp. 271279, 2008.

[25] J. King, R. Quinn, D. M. Glenn et al., "Radioembolization with selective internal radiation microspheres for neuroendocrine liver metastases," Cancer, vol. 113, no. 5, pp. 921-929, 2008.

[26] L. K. Kvols, C. G. Moertel, and M. J. O’Connell, “Treatment of the malignant carcinoid syndrome. Evaluation of a long-acting somatostatin analogue," New England Journal of Medicine, vol. 315, no. 11, pp. 663-666, 1986.

[27] M. Di Bartolomeo, E. Bajetta, R. Buzzoni et al., "Clinical efficacy of octreotide in the treatment of metastatic neuroendocrine tumors: a study by the Italian Trials in Medical Oncology Group," Cancer, vol. 77, no. 2, pp. 402-408, 1996.

[28] D. O'Toole, M. Ducreux, G. Bommelaer et al., "Treatment of carcinoid syndrome: a prospective crossover evaluation of lanreotide versus octreotide in terms of efficacy, patient acceptability, and tolerance," Cancer, vol. 88, no. 4, pp. 770 776, 2000.

[29] A. Rinke, H. H. Müller, C. Schade-Brittinger et al., "Placebocontrolled, double-blind, prospective, randomized study on the effect of octreotide LAR in the control of tumor growth in patients with metastatic neuroendocrine midgut tumors: a report from the PROMID study group," Journal of Clinical Oncology, vol. 27, no. 28, pp. 4656-4663, 2009.

[30] W. A. Breeman, M. De Jong, D. J. Kwekkeboom et al., "Somatostatin receptor-mediated imaging and therapy: basic science, current knowledge, limitations and future perspectives," European Journal of Nuclear Medicine, vol. 28, no. 9, pp. 1421-1429, 2001.

[31] J. J. M. Teunissen, D. J. Kwekkeboom, M. de Jong, J.-P. Esser, R. Valkema, and E. P. Krenning, "Peptide receptor radionuclide therapy," Best Practice and Research: Clinical Gastroenterology, vol. 19, no. 4, pp. 595-616, 2005.

[32] D. L. Bushnell Jr., T. M. O’Dorisio, M. S. O’Dorisio et al., “90Yedotreotide for metastatic carcinoid refractory to octreotide," Journal of Clinical Oncology, vol. 28, no. 10, pp. 1652-1659, 2010.

[33] D. J. Kwekkeboom, W. W. De Herder, B. L. Kam et al., "Treatment with the radiolabeled somatostatin analog [177LuDOTA0,Tyr3] octreotate: toxicity, efficacy, and survival," Journal of Clinical Oncology, vol. 26, no. 13, pp. 2124-2130, 2008.

[34] W. Sun, S. Lipsitz, P. Catalano, J. A. Mailliard, and D. G. Haller, "Phase II/III study of doxorubicin with fluorouracil compared with streptozocin with fluorouracil or dacarbazine in the treatment of advanced carcinoid tumors: Eastern Cooperative Oncology Group Study E1281," Journal of Clinical Oncology, vol. 23, no. 22, pp. 4897-4904, 2005.

[35] E. Raymond, L. Dahan, J.-L. Raoul et al., "Sunitinib malate for the treatment of pancreatic neuroendocrine tumors," New England Journal of Medicine, vol. 364, no. 6, pp. 501-513, 2011.

[36] J. C. Yao, M. H. Shah, T. Ito et al., "Everolimus for advanced pancreatic neuroendocrine tumors," New England Journal of Medicine, vol. 364, no. 6, pp. 514-523, 2011.

[37] J. C. Yao, A. Phan, P. M. Hoff et al., "Targeting vascular endothelial growth factor in advanced carcinoid tumor: a random assignment phase ii study of depot octreotide with bevacizumab and pegylated interferon alfa-2b," Journal of Clinical Oncology, vol. 26, no. 8, pp. 1316-1323, 2008.

[38] T. J. Hobday, J. Rubin, K. Holen et al., "MC044h, a phase II trial of sorafenib in patients (pts) with metastatic neuroendocrine tumors (NET): a Phase II Consortium (P2C) study," Journal of Clinical Oncology, vol. 25, no. 18S, p. 4504, 2007.

[39] M. H. Kulke, H. J. Lenz, N. J. Meropol et al., "Activity of sunitinib in patients with advanced neuroendocrine tumors," Journal of Clinical Oncology, vol. 26, no. 20, pp. 3403-3410, 2008.

[40] J. Capdevila, A. Teule, D. E. Castellano et al., "PAZONET: a phase II trial of pazopanib in patients with metastatic neuroendocrine tumors (NETs) who may have previously received antiangiogenic or mTOR treatment," Journal of Clinical Oncology, vol. 29, abstract TPS171, 2011.

[41] I. Duran, J. Kortmansky, D. Singh et al., "A phase II clinical and pharmacodynamic study of temsirolimus in advanced neuroendocrine carcinomas," British Journal of Cancer, vol. 95, no. 9, pp. 1148-1154, 2006.

[42] J. C. Yao, A. T. Phan, D. Z. Chang et al., "Efficacy of RAD001 (everolimus) and octreotide LAR in advanced low- to intermediate-grade neuroendocrine tumors: results of a phase II study," Journal of Clinical Oncology, vol. 26, no. 26, pp. 43114318, 2008.

[43] J. C. Yao, C. Lombard-Bohas, E. Baudin et al., "Daily oral everolimus activity in patients with metastatic pancreatic neuroendocrine tumors after failure of cytotoxic chemotherapy: a phase II trial," Journal of Clinical Oncology, vol. 28, no. 1, pp. 69-76, 2010. 
[44] T. Ito, T. Okusaka, M. Ikeda et al., "Everolimus versus placebo in Japanese patients with advanced pancreatic neuroendocrine tumors (pNET): Japanese subgroup analysis of RADIANT-3," Journal of Clinical Oncology, vol. 29, supplement 4, abstract 289, 2011.

[45] M. Kulke, L. S. Blaszkowsky, A. X. Zhu et al., "Phase I/II study of everolimus (RAD001) in combination with temozolomide (TMZ) in patients (pts) with advanced pancreatic neuroendocrine tumors (NET)," in Proceedings of the Gastrointestinal Cancers Symposium, 2010. 


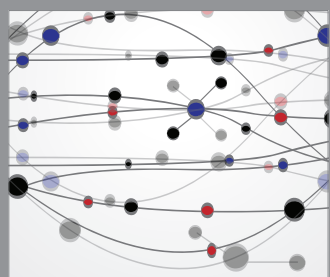

The Scientific World Journal
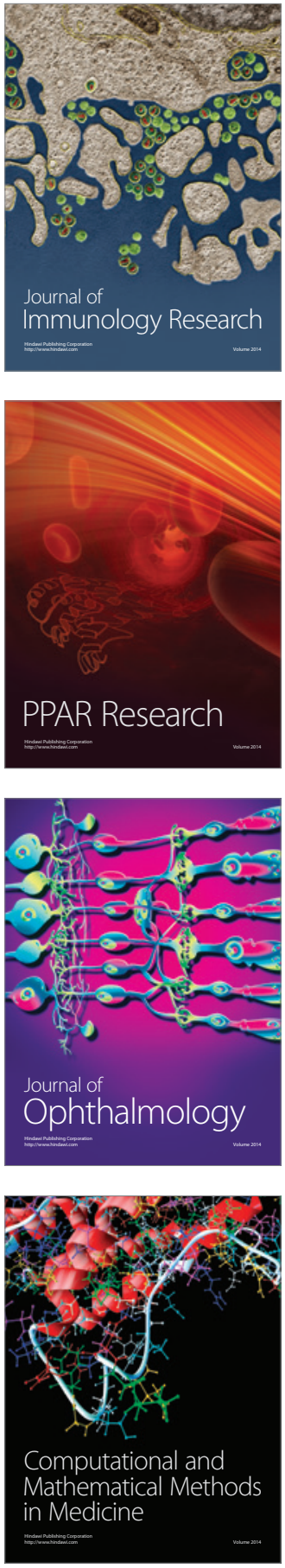

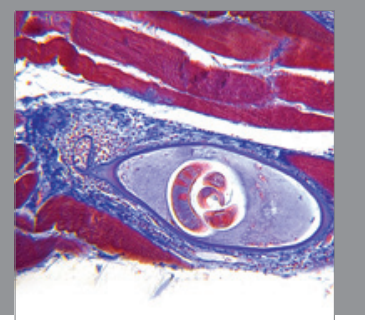

Gastroenterology

Research and Practice
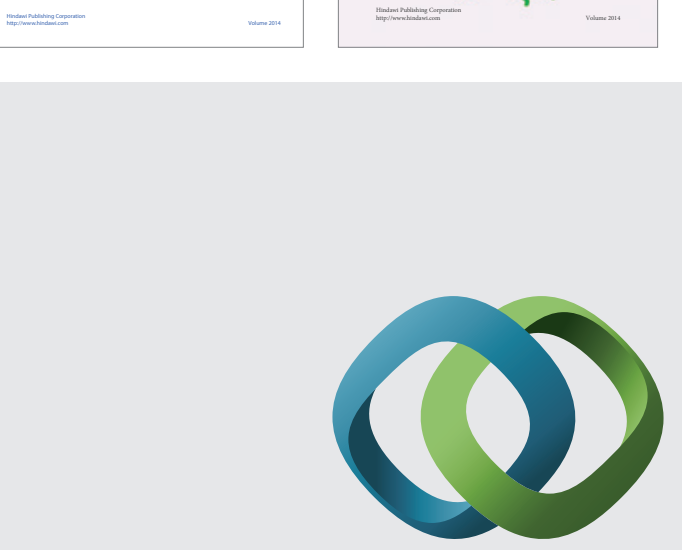

\section{Hindawi}

Submit your manuscripts at

http://www.hindawi.com
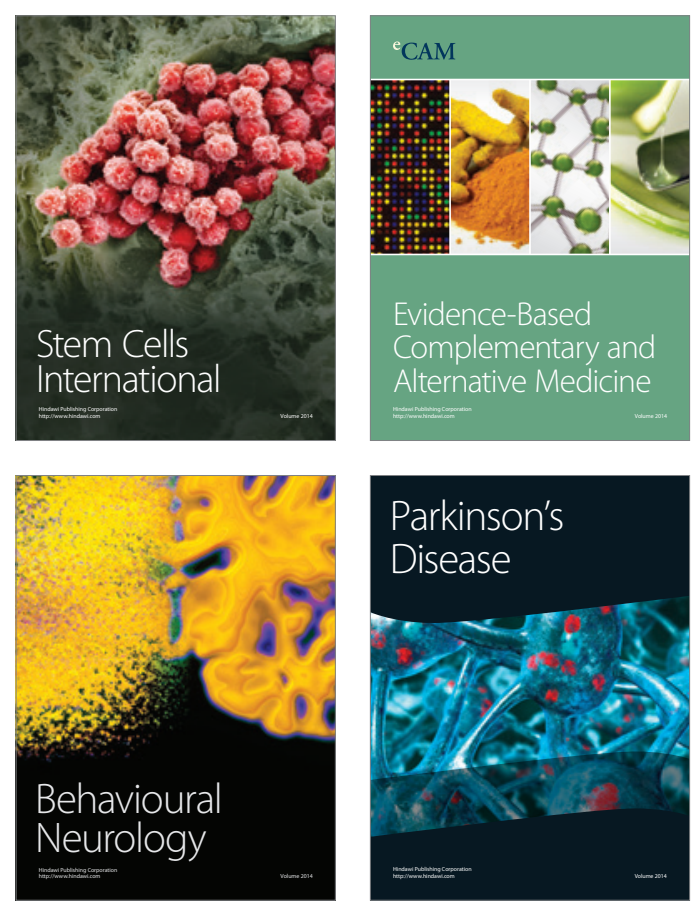

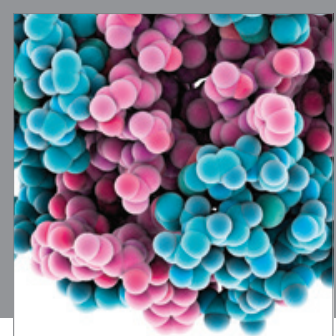

Journal of
Diabetes Research

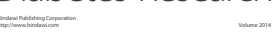

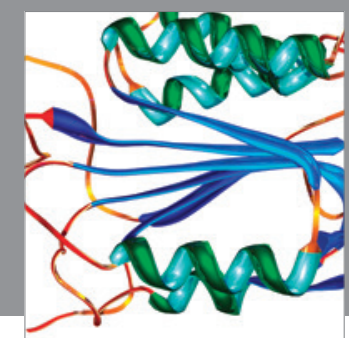

Disease Markers
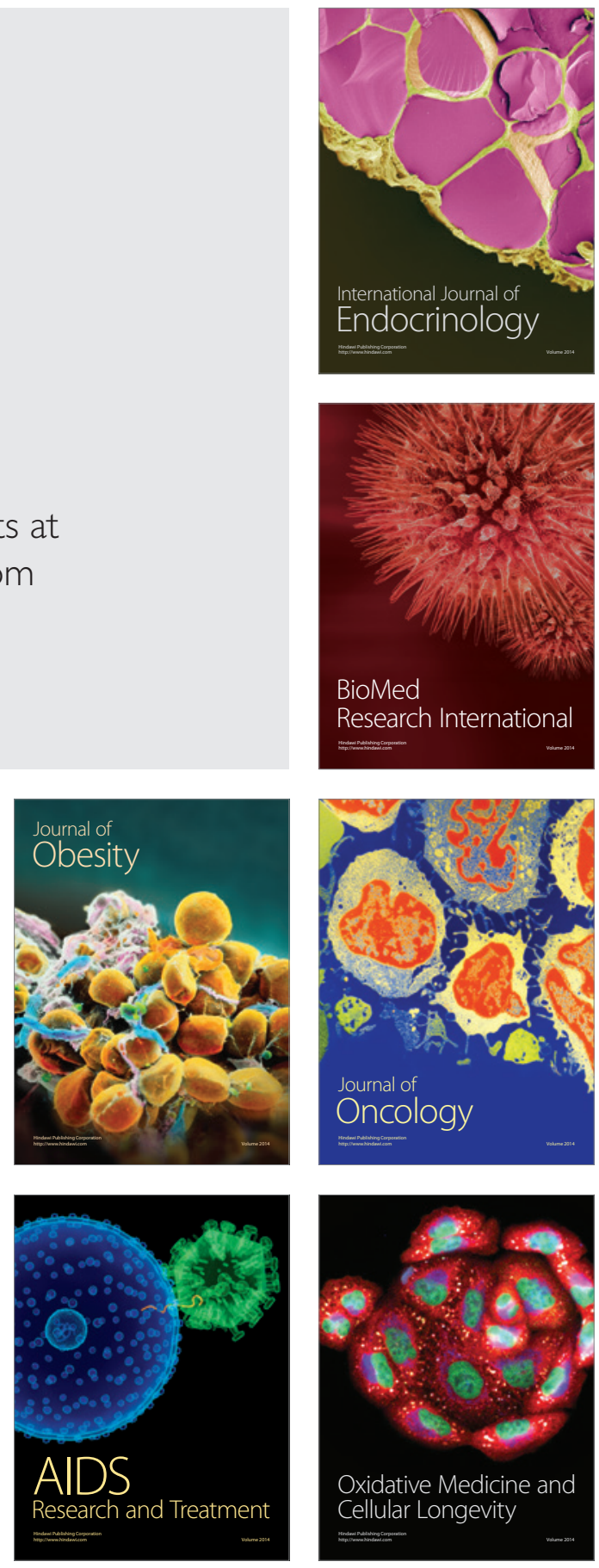